Carta ao Editor

Letter to Editor

Vanessa Souza Gigoski de Miranda1 1 (1)

Rafaela Soares Rech ${ }^{2}$

Márcia Angélica Peter Maahs ${ }^{1}$

Monalise Costa Batista Berbert ${ }^{1}$ ca

Sheila Tamanini de Almeida ${ }^{1}$ (1)

\section{Fonoaudiologia, amamentação e COVID-19: informações aos fonoaudiólogos}

\section{Speech therapy, breastfeeding and COVID-19: information to speech therapist}

Durante os primeiros meses de 2020, um novo vírus se espalhou rapidamente para países do mundo todo, o SARS-CoV 2. A Organização Mundial da Saúde (OMS) denominou a doença causada por este vírus de Coronavirus Disease 19 (COVID-19) ${ }^{1}$. As manifestações mais comuns do COVID-19 consistem em febre, tosse e fadiga ou mialgia, produção de escarro e dor de cabeça ${ }^{2-4}$.

Dados de coronavírus anteriores (SARS-CoV e MERS-CoV) mostraram que as grávidas poderiam estar em grupos de risco com chance de ter morbimortalidade maior que a população em geral ${ }^{5}$. Porém, pouco se sabe sobre o COVID-19 nessa população ${ }^{5}$. Em um estudo realizado em Wuhan ${ }^{6}$ - primeira cidade epicentro da doença, pesquisadores relataram nove nascidos vivos de mães positivas para COVID-19, e todas as amostras foram negativas para o vírus nos neonatos. Suas descobertas apoiaram que atualmente não há evidências de transmissão vertical em mães infectadas no final da gravidez ${ }^{6}$.

Embora o COVID-19 possa afetar indivíduos de todas as faixas etárias, a doença geralmente é mais leve em crianças do que em adultos, especialmente em neonatos? Os sintomas clínicos mais comuns na população pediátrica incluem febre, fadiga e tosse seca. Alguns pacientes apresentam manifestações respiratórias superiores, como obstrução nasal, secreção nasal e dor de garganta, e outros apresentam sintomas gastrointestinais, como desconforto abdominal, vômito, dor abdominal e diarreia ${ }^{6}$.

Atualmente, não há evidências de que o Corona Vírus possa ser transmitido através do leite materno, mas é sabido que uma mãe infectada pode transmitir o vírus através de gotículas respiratórias durante a amamentação ${ }^{8}$. Em estudo realizado com seis recémnascidos de mães infectadas, que amamentavam seus bebês, todas as amostras foram negativas para o vírus ${ }^{6}$.

O fonoaudiólogo que necessitar avaliar bebês de puérperas confirmadas e/ou suspeitas de COVID-19 devem seguir as recomendações de uso de utensílios de proteção como os demais profissionais de saúde: gorros, óculos de proteção, roupas de proteção, luvas, máscaras N95. Neonatologistas orientam que nenhuma visita deve ser permitida para neonatos com diagnóstico, ou com mães com suspeita ou diagnóstico de COVID - $19^{7}$. As orientações para a amamentação da Sociedade Italiana de Neonatologia (SIN), endossadas pela União Europeia de Neonatologia e Sociedades Perinatais (UENPS) são: se uma mãe previamente identificada como COVID - 19 positiva ou sob suspeita para COVID - 19 for assintomática no momento do parto, a amamentação direta é aconselhável, sob rigorosas medidas de controle de infecção; e quando uma mãe com COVID-19 está doente demais para cuidar do recém-nascido, o recém-nascido será tratado separadamente e alimentado com leite materno expresso fresco, sem a necessidade de pasteurizá-lo, pois não há evidências de que o leite humano seja possível transmissor do COVID-199.

Trabalho realizado no Departamento de Fonoaudiologia, Universidade Federal de Ciências da Saúde de Porto Alegre - UFCSPA - Porto Alegre (RS), Brasil.

${ }^{1}$ Universidade Federal de Ciências da Saúde de Porto Alegre - UFCSPA - Porto Alegre (RS), Brasil.

${ }^{2}$ Universidade Federal do Rio Grande do Sul - UFRGS - Porto Alegre (RS), Brasil.

Fonte de financiamento: nada a declarar

Conflito de interesses: nada a declarar. 
Segundo o Centro de Controle de Prevenção de Doenças (2020) medidas devem ser tomadas para diminuir a chance de transmissão viral durante a amamentação, como: evitar beijar o recém-nascido, protegê-lo da tosse adulta, utilizar máscara durante a amamentação, higienizar as mãos antes da mamada e suspender as visitas. Ainda, quando o bebê estiver em alojamento conjunto com a mãe doente, o bebê deve permanecer a uma distância de no mínimo 2 metros da mãe, com a presença de uma barreira física entre eles, como por exemplo, uma cortina ${ }^{9,10}$. A OMS orienta também que sejam limpas e desinfetadas regularmente as superfícies que a mãe contaminada tenha contato ${ }^{1}$.

Quanto ao armazenamento de leite humano, a OMS recomenda que mães com suspeita ou confirmação de COVID -19 utilizem os mesmos cuidados indicados na hora da amamentação: higienização das mãos, uso de máscara, desinfetar superfícies de contato. Indicam que o recipiente que recebeu o leite humano deve ter a parte externa desinfetada após a extração do mesmo, com soluções sanitárias adequadas, antes do armazenamento em bancos de leite, enfermarias ou na residência da própria puérpera ${ }^{11}$. Com a propagação da doença, e o crescente número de gestantes e puérperas que poderão apresentar os sintomas - mas em testagem do vírus - a recomendação da OMS é de que todas as puérperas que doam e que recebem leite dos bancos de leite humanos sigam essas recomendações de higiene pré, peri e durante o recebimento do frasco. Ainda, para mães infectadas com o COVID- 19 que precisarem extrair o leite em ambiente hospitalar com uso de bombas, esses aparelhos deverão ser de uso individual dessa puérpera ${ }^{11,12}$.

São poucas e frágeis as evidências a respeito do COVID-19e a amamentação até o momento, assim como frente à outras áreas. A ciência vai tomando forma e as instituições elaborando suas recomendações de acordo com o curso de evolução da doença. Identificou-se que a amamentação é, até o momento, indicada nos casos de suspeita e confirmação da COVID-19, com controle de infecção ${ }^{9-11}$ e higienização. Além disso, todas as mães que doam e que recebem leite de bancos de leite humanos devem realizar desinfecção dos frascos antes de manusear, mesmo que essa não apresente sintomas do vírus.

A Sociedade Brasileira de Pediatria referiu em nota, ser favorável à manutenção da amamentação em mães portadoras do COVID-19, diante das atuais evidências ${ }^{13}$. O fonoaudiólogo como membro atuante na Educação em Saúde, apresenta atuação e intervenção positiva na orientação da amamentação ${ }^{14}$, deve estar atualizado e acompanhando as novas recomendações das grandes organizações internacionais, assim como o odontólogo e demais profissionais da saúde, pois a amamentação adequada estimula o crescimento e desenvolvimento craniofacial harmonioso ${ }^{15}$.

\section{REFERÊNCIAS}

1. WHO: World Health Organization. Coronavirus disease (COVID-19) outbreak situation [Internet]. Geneva: WHO; 2019 [citado em 2020 Apr 20]. Disponível em: https://www.who.int/emergencies/diseases/novel-coronavirus-2019
2. Ma K, Chen T, Han MF, Guo W, Ning Q. Management and clinical thinking of Coronavirus Disease 2019. Zhonghua Gan Zang Bing Za Zhi. 2020;28:E002. PMid:32125126.

3. Zhu ZB, Zhong CK, Zhang KX, Dong C, Peng H, Xu T, et al. Epidemic trend of corona virus disease 2019 (COVID-19) in mainland China. Zhonghua Yu Fang Yi Xue Za Zhi. 2020;54(0):E022. PMid:32125133.

4. Yang HY, Duan GC. Analysis on the epidemic factors for the Corona Virus Disease. Zhonghua Yu Fang Yi Xue Za Zhi. 2020;54(0):E021. PMid:32125129.

5. Karimi-Zarchi M, Neamatzadeh H, Dastgheib SA, Abbasi H, Mirjalili SR, Behforouz A, et al. (2020). Vertical transmission of coronavirus disease 19 (COVID-19) from infected pregnant mothers to neonates: a review. Fetal Pediatr Pathol. 1-5. https://doi.org/10.1080/1551381 5.2020 .1747120 .

6. Chen H, Guo J, Wang C, Luo F, Yu X, Zhang W, et al. Clinical characteristics and intrauterine vertical transmission potential of COVID-19 infection in nine pregnant women: a retrospective review of medical records. Lancet. 2020;395(10226):809-15. http://dx.doi. org/10.1016/S0140-6736(20)30360-3. PMid:32151335.

7. Lu Q, Shi Y. Coronavirus disease (COVID-19) and neonate: what neonatologist need to know. J Med Virol. 2020;92(6):564-7. http:/ dx.doi.org/10.1002/jmv.25740. PMid:32115733.

8. Rasmussen SA, Smulian JC, Lednicky JA, Wen TS, Jamieson DJ. Coronavirus disease 2019 (COVID-19) and pregnancy: what obstetricians need to know. Am J Obstet Gynecol. 2020;pii: S00029378(20):30197-6.

9. Davanzo R, Moro G, Sandri F, Agosti M, Moretti C, Mosca F. Breastfeeding and Coronavirus Disease-2019. Ad interim indications of the Italian Society of Neonatology endorsed by the Union of European Neonatal \& Perinatal Societies. Matern Child Nutr. 2020;e13010. PMid:32243068.

10. CDC: Centers of Disease Control and Prevention. Coronavirus disease 2019 [Internet]. Atlanta: CDC; 2019 [citado em $2020 \mathrm{Apr}$ 7]. Disponível em: https://www.cdc.gov/coronavirus/2019-ncov/hcp/ inpatient-obstetric-healthcare-guidance.html

11. WHO: World Health Organization. Infection prevention and control during health care when COVID-19 is suspected: interim guidance. Geneva: WHO; 2020 [citado em 2020 Apr 7]. Disponível em: https:// apps.who.int/iris/handle/10665/331495

12. Marinelli KA, Lawrence RM. Safe handling of containers of expressed human milk in all settings during the SARS-CoV-2 (COVID-19) Pandemic. J Hum Lact. In press 2020;890334420919083. PMid:32242762.

13. Sociedade Brasileira de Pediatria. O aleitamento materno nos tempos de COVID-19! No. 9. São Paulo: Departamento Científico de Aleitamento Materno; 2020. Nota de Alerta.

14. Medeiros AMC, Santos JCJ, Santos DAR, Barreto IDC, Alves YVT, Acompanhamento fonoaudiológico do aleitamento materno em recém-nascidos nas primeiras horas de vida. Audiol Commun Res. 2017;22:e1856. http://dx.doi.org/10.1590/2317-6431-2017-1856.

15. Leite ICG, Pinheiro AM, Brum LRG, Souza AS, Marinho SBA. Relação da amamentação com o desenvolvimento do sistema estomatognático. J Bras Fonoaudiol. 2002;3:237-42.

\section{Contribuição dos autores}

VSGM, RSR participaram da idealização, seleção e análise dos estudos, e redação do artigo científico; MAPM, MCBB e STA participaram da análise e interpretação dos dados, escrita e revisão científica do artigo. 